\title{
Kinetic spectrophotometric determination of an important pharmaceutical compound, pregabalin
}

Raafia Najam ${ }^{1 \dagger}$, Gh Mohd Shah ${ }^{1 \dagger}$ and S Muzaffar Ali Andrabi ${ }^{2^{* \dagger}}$

\begin{abstract}
Background: Pregabalin (PGB), an anticonvulsant, was studied throughout this work using spectrophotometric method.

Methods: The spectrophotometric method is based on the condensation reaction of PGB with

$p$-dimethylaminobenzaldehyde ( $p D M A B)$ in acid medium. The condensation product showed $\lambda_{\max }$ at $420 \mathrm{~nm}$.

Results: The different parameters affecting the stability of the condensation product were carefully studied and optimized. The calibration plots were constructed over the concentration range of 40 to $120 \mathrm{\mu g} \mathrm{ml}^{-1}$.

Conclusions: A simple, reliable, sensitive and accurate spectrophotometric method has been developed for the determination of an anticonvulsant drug, PGB. The proposed method was successfully applied to the analysis of the drug in dosage form. The high sensitivity of the proposed method allows determination of PGB in bulk and in pharmaceutical preparations.
\end{abstract}

Keywords: PGB; pDMAB; Spectrophotometric determination; Capsules

\section{Background}

Pregabalin (PGB), (S)-3-(aminomethyl)-5-methyl hexanoic acid is an antiepileptic and structurally related to the inhibitory neurotransmitter aminobutyric acid (GABA). It is a white crystalline solid with molecular formula $\mathrm{C}_{8} \mathrm{H}_{17} \mathrm{NO}_{2}$, molecular mass of $159.23 \mathrm{~g} / \mathrm{mol}$ and melting point from $190^{\circ} \mathrm{C}$ to $192^{\circ} \mathrm{C}$. It was approved in the year 2007 for adjunctive treatment of partial seizures in adults (Tassone et al. 2007; Hamandi and Sander 2006; Barona et al. 2008) in United States and Europe, and for the treatment of neuropathic pain from post-therapeutic neuralgia and diabetic neuropathy.

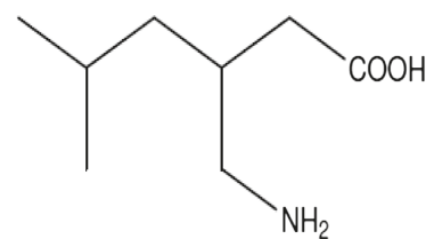

PREGABALIN

\footnotetext{
* Correspondence: muzaffar2000@gmail.com

${ }^{\dagger}$ Equal contributors

${ }^{2}$ University Science Instrumentation Centre, University of Kashmir, Srinagar, Jammu and Kashmir 190006, India

Full list of author information is available at the end of the article
}

The wide use of this drug has prompted many researches to develop sensitive and accurate analytical methods for its determination, especially for routine quality control in the analysis of pharmaceutical products. Several methods have been developed for the determination of the drug in pure and pharmaceutical preparations which are mostly based on chromatographic, spectrofluorimetric and spectrophotometric methods listed elsewhere (Bali and Gaur 2011). A detailed literature survey shows that few spectrophotometric methods have been developed for the determination of PGB in bulk and pharmaceutical preparation. A sensitive and selective spectrophotometric method, based on the reaction of the drug with 7-chloro-4-nitrobenzofuran, has been developed for the determination of PGB by Onal and Sagirli (2009). The relation between the absorbance of the reaction product at $460 \mathrm{~nm}$ and the concentration is rectilinear over the range 0.5 to $7.0 \mu \mathrm{g} / \mathrm{ml}$. Gujral et al. (2009) developed a simple and sensitive method for the determination of PGB in bulk and pharmaceutical formulations. The method is based on the reaction of the drug with a mixture of potassium iodate and potassium iodide. The method is linear over the range 0.5 to $3.5 \mu \mathrm{g} / \mathrm{ml}$. Onal (2009) developed three methods for the determination of PGB in pharmaceutical preparations. Two methods are based on the charge transfer complexation of the drug with 
2,3-dichloro-5,6-dicyano-1,4-benzoquinone (DDQ) and 7,7, 8,8-tetracyanoquinodimethane (TCNQ), and the third method was based on the reaction of ninhydrin with the primary amine group on the drug molecule. While the first two methods were linear over the concentration ranges of 2.0 to 30 and 1.5 to $10 \mu \mathrm{g} / \mathrm{ml}$, respectively, the third method was linear over a much wider concentration range of 40 to $180 \mu \mathrm{g} / \mathrm{ml}$. Two simple spectrophotometric methods for the quantitative estimation of PGB in bulk and pharmaceutical formulations were developed by Sowjanya et al. (2011). The first method is based on the condensation of PGB with 1,2-naphthaquinone-4-sulfonic acid sodium in alkaline medium, and the second method is based on the oxidation of 2,4-dinitrophenyhydrazine and the coupling of the oxidation product with the drug to give intensely coloured chromogen. The first method is linear over the concentration range of 5 to $45 \mu \mathrm{g} / \mathrm{ml}$, and the second method is linear over the range of 50 to $450 \mu \mathrm{g} / \mathrm{ml}$. Reddy (2013) developed a spectrophotometric method for determination of PGB in bulk and pharmaceutical dosage form. The method is based on the reaction of PGB with DDQ to form red colour charge-transfer complex. Beer's law is obeyed in the concentration range of 50 to $250 \mu \mathrm{g} / \mathrm{ml}$ for the method. UV-visible spectroscopy is the technique of choice for the accurate and cost-effective determination of pharmaceutical compounds especially in third world countries. Consequently, there is scope for the development of simple and accurate spectrophotometric methods for the determination of pregabalin in bulk and pharmaceutical formulations.
In this study, $p$-dimethylaminobenzaldehyde ( $p$ DMAB) has been used as a chromogenic agent for the determination of pregabalin. $p$ DMAB possesses some peculiar structural features which account for its applicability in a wide range of reactions and processes. Its condensation reactions have been utilized for the spectrophotometric determination of many drugs (Adegoke and Umoh 2009; Adegoke and Nwoke 2008). An attempt has been made to develop a simple, accurate, rapid and economical method for determination of pregabalin in pure and pharmaceutical formulations. The method is based on the reaction of pregabalin with $p$ DMAB in acidic medium. The method involves a one-step reaction, does not involve any extraction or heating steps and does not require any costly chemicals and equipment. The reaction is monitored spectrophotometrically, and the change in absorbance with time is measured at $420 \mathrm{~nm}$.

\section{Methods}

\section{Instrumentation}

A Systronics UV-visible spectrophotometer (model 118, Gujarat, India) with $1-\mathrm{cm}$ matched quartz cells was used for the absorbance measurements. Shimadzu electronic balance (Kyoto, Japan) was used for weighing the samples.

\section{Materials}

All the chemicals and materials were of analytical grade and were purchased from Qualigens Fine Chemicals Pvt. Ltd. (Mumbai, India), and Deccan Fine Chemicals India Limited (Hyderabad, India). All the solutions were

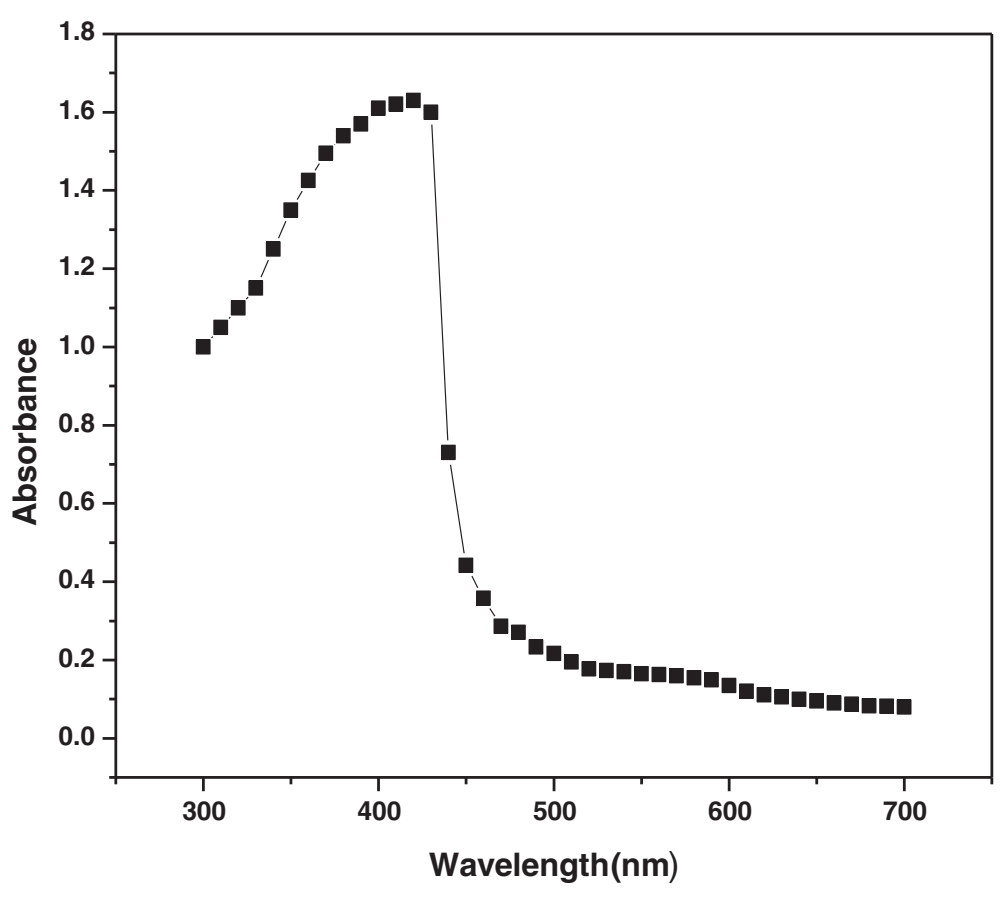

Figure 1 UV-visible spectrum of the product of PGB and pDMAB $\left(\lambda_{\max } 420 \mathrm{~nm}\right)$. 


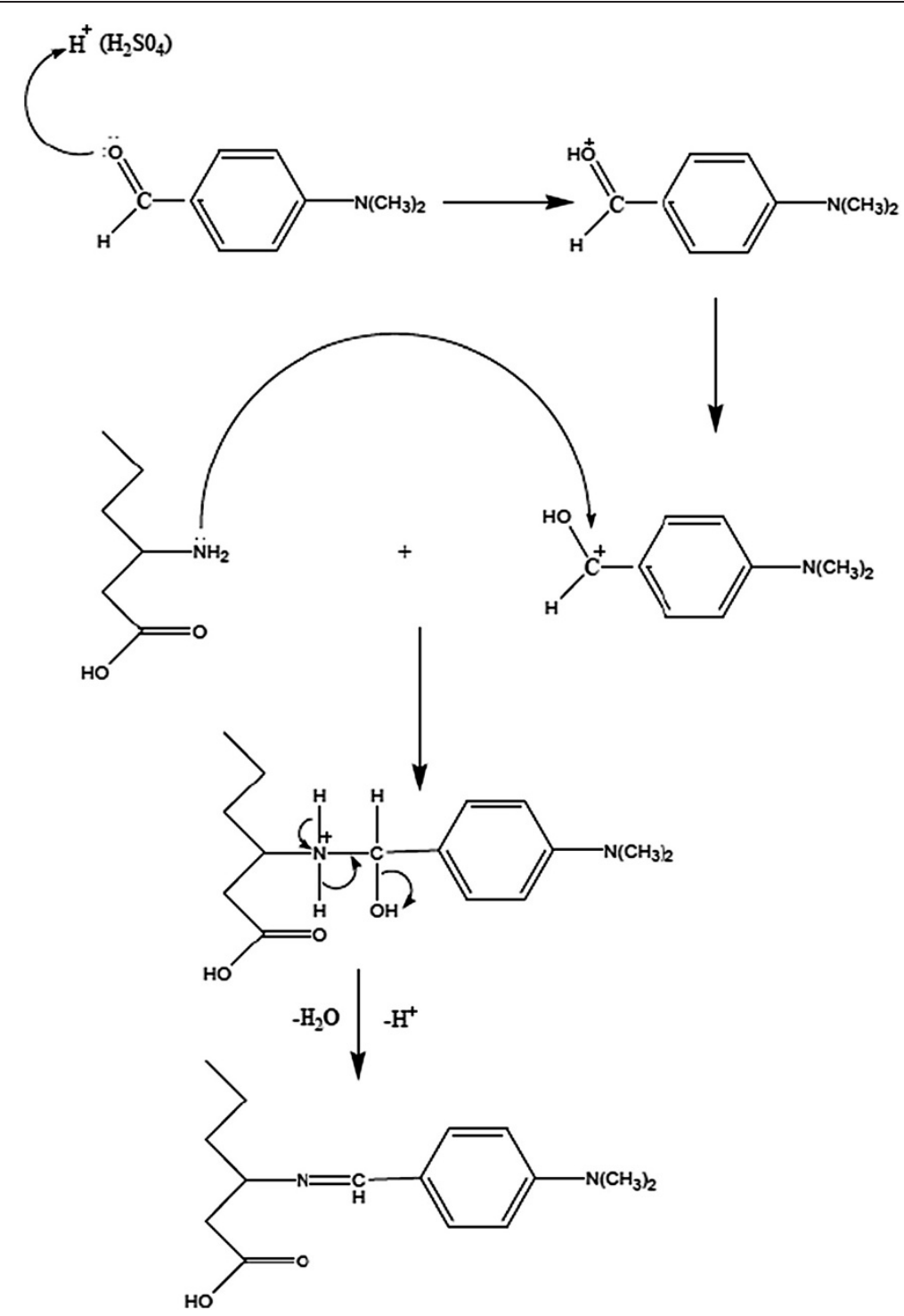

Scheme 1 Probable mechanism of the reaction between $p$ DMAB and PGB in acid medium.

freshly prepared. PGB, AR grade, was purchased from Himedia Laboratories (Mumbai, India), and PGB 75 capsules (label amount $75 \mathrm{mg}$ PGB/capsule) of various pharmaceutical manufactures were purchased from the market.

\section{Preparation of the standard solutions}

Stock solution of PGB $(1,000 \mu \mathrm{g} / \mathrm{ml})$ was prepared by dissolving $100 \mathrm{mg}$ of drug in $10 \mathrm{ml}$ of $0.5 \mathrm{M} \mathrm{H}_{2} \mathrm{SO}_{4}$ and diluting up to the mark by ethanol in a $100-\mathrm{ml}$ calibrated flask. The stock solution was further diluted appropriately to get working concentrations. $p \mathrm{DMAB}$ $(0.3 \% \mathrm{w} / \mathrm{v})$ was made by dissolving $0.3 \mathrm{~g}$ in $100 \mathrm{ml}$ of $0.5 \mathrm{M} \mathrm{H}_{2} \mathrm{SO}_{4}$.

\section{General procedure}

\section{Construction of calibration curve}

To a set of 10-ml volumetric flasks, appropriate aliquots of the standard working solution were transferred to obtain concentrations in the range 40 to $120 \mu \mathrm{g} \mathrm{ml}^{-1}$ of PGB. Aliquots of standard solution of pregabalin were mixed with $2 \mathrm{ml}$ of $0.3 \% p \mathrm{DMAB}$, and the contents were diluted up to $10 \mathrm{ml}$ with ethanol and time was noted. The reaction mixture was rapidly transferred into a cuvette, and absorbance at $420 \mathrm{~nm}$ was recorded after every 5 min against the reagent blank prepared simultaneously in the same manner without the analyte. First, absorbance was taken exactly 5 min after mixing PGB and $p$ DMAB solutions. The procedure was repeated for different concentrations of the drug solution, with a constant concentration of $p \mathrm{DMAB}$ 


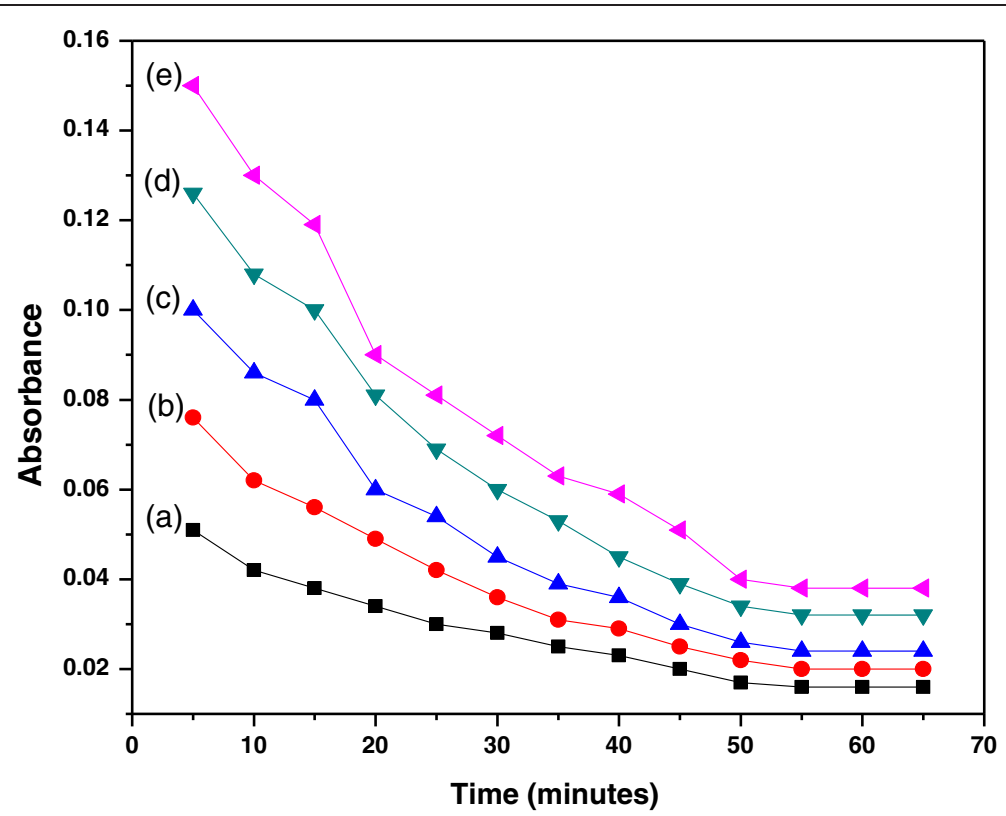

Figure 2 Variation of absorbance of drug-reagent mixture with time. (a) $40 \mu \mathrm{g} / \mathrm{ml}$, (b) $60 \mu \mathrm{g} / \mathrm{ml}$, (c) $80 \mu \mathrm{g} / \mathrm{ml}$, (d) $100 \mu \mathrm{g} / \mathrm{ml}$, and (e) $120 \mu \mathrm{g} / \mathrm{ml}$.

solution. All the experiments are carried out at room temperature. The regression equations of calibration graphs were calculated using the method of least squares.

\section{Assay of capsules}

An accurately weighed portion of powder from tablets purchased from open market equivalent to $100 \mathrm{mg}$ of PGB was put in a $100-\mathrm{ml}$ volumetric flask containing $10 \mathrm{ml}$ of
$\mathrm{H}_{2} \mathrm{SO}_{4}$ and was diluted up to the mark using ethanol. It was shaken thoroughly for about 5 to $10 \mathrm{~min}$, filtered through a Whatman paper to remove insoluble matter and used to prepare $1,000 \mu \mathrm{g} / \mathrm{ml}$ using ethanol for dilution. An aliquot of this solution was diluted with ethanol to obtain a required concentration (40 to $120 \mu \mathrm{g} / \mathrm{ml}$ ). Then, to a solution of particular concentration, $2 \mathrm{ml}$ of $0.3 \% p$ DMAB was added and gently shaken. The contents were diluted

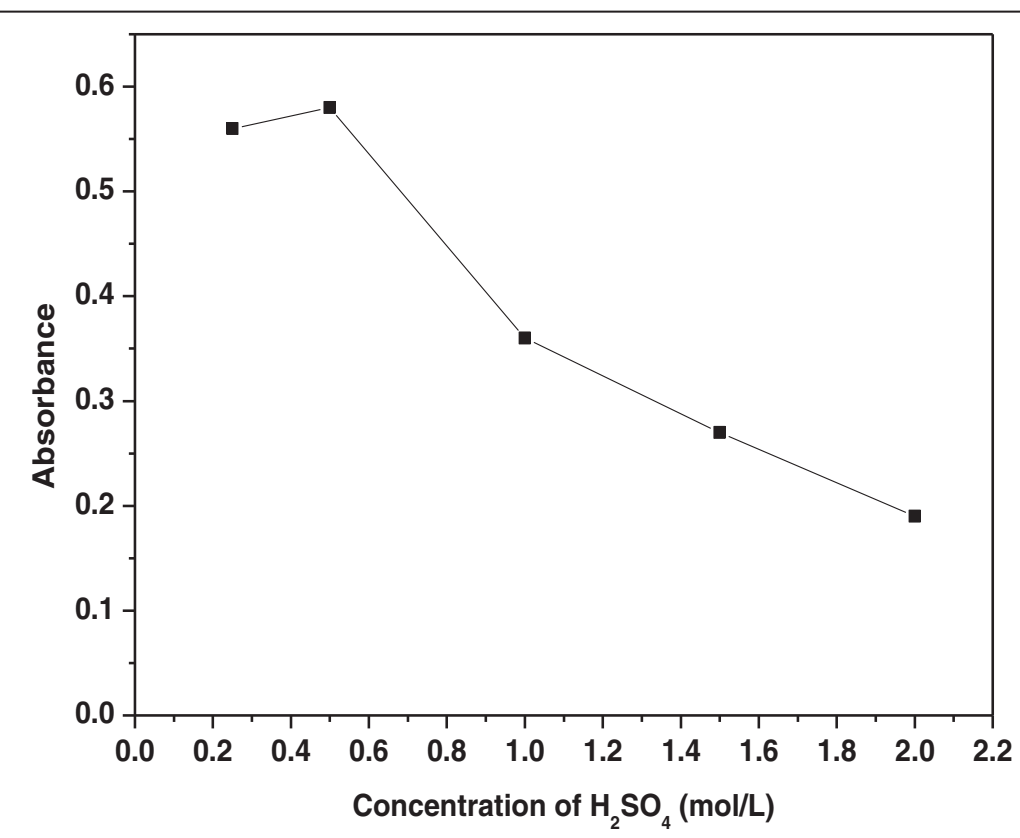

Figure 3 Effect of acid concentration on absorbance of drug-reagent mixture. 


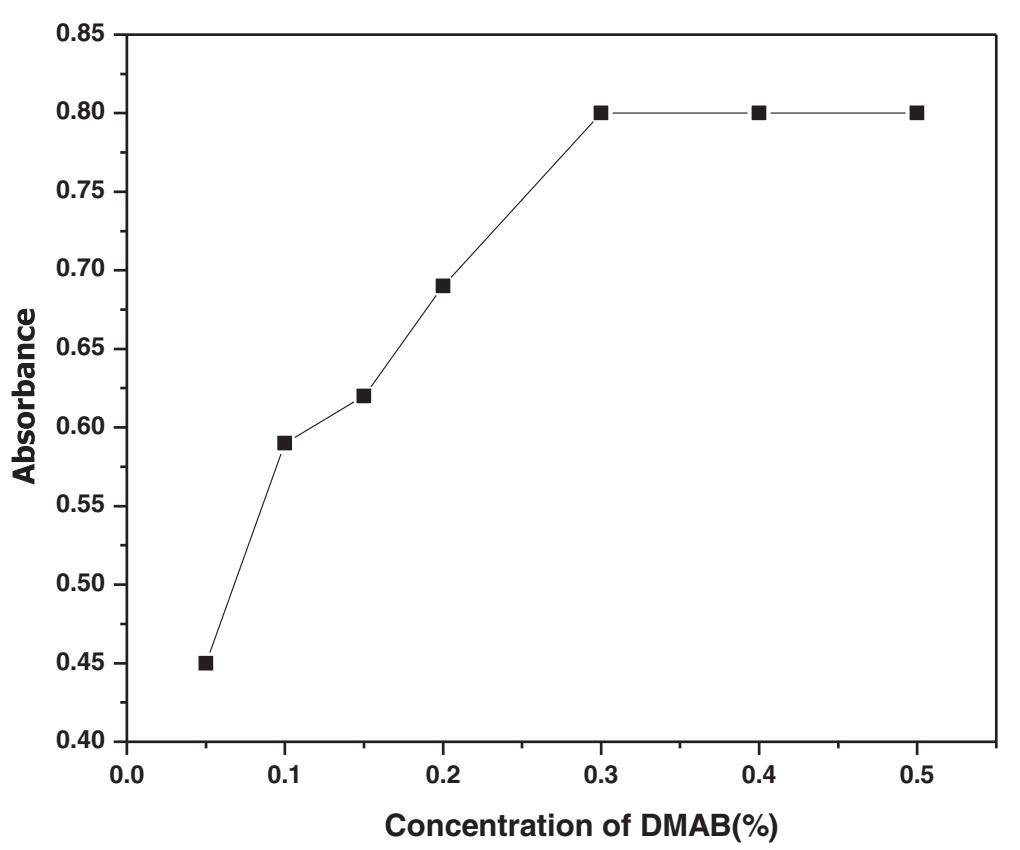

Figure 4 Effect of concentration of $p D M A B$ on absorbance of drug-reagent mixture.

up to $10 \mathrm{ml}$ with ethanol. The nominal content of the capsules was determined using the corresponding regression equations or the calibration graphs.

\section{Results and discussions}

In an effort to develop a spectrophotometric method for quantification of pregabalin, its reaction with $p \mathrm{DMAB}$ in an acid medium for the generation of a chromophoric product was studied. PGB reacts instantly with $p$ DMAB in an acid medium to give a light yellow colour $\left(\lambda_{\max }\right.$ at $420 \mathrm{~nm})$. PGB shows a $\lambda_{\max }$ at $180 \mathrm{~nm}$ and does not absorb in the visible region at all, while $p$ DMAB shows $\lambda_{\max }$ at $280 \mathrm{~nm}$. The UV-visible spectrum of the product of the reaction between $\mathrm{PGB}$ and $p \mathrm{DMAB}$ is given in Figure 1. The probable mechanism of the reaction between $p \mathrm{DMAB}$ and $\mathrm{PGB}$ in acid medium is given in Scheme 1.

The condensation reaction requires the presence of an acid for the protonation of the carbonyl oxygen and thereby leaving the carbonyl carbon fully positively charged. The PGB then donates a lone pair of electrons to the carbon. Internal rearrangement thereafter results in the formation

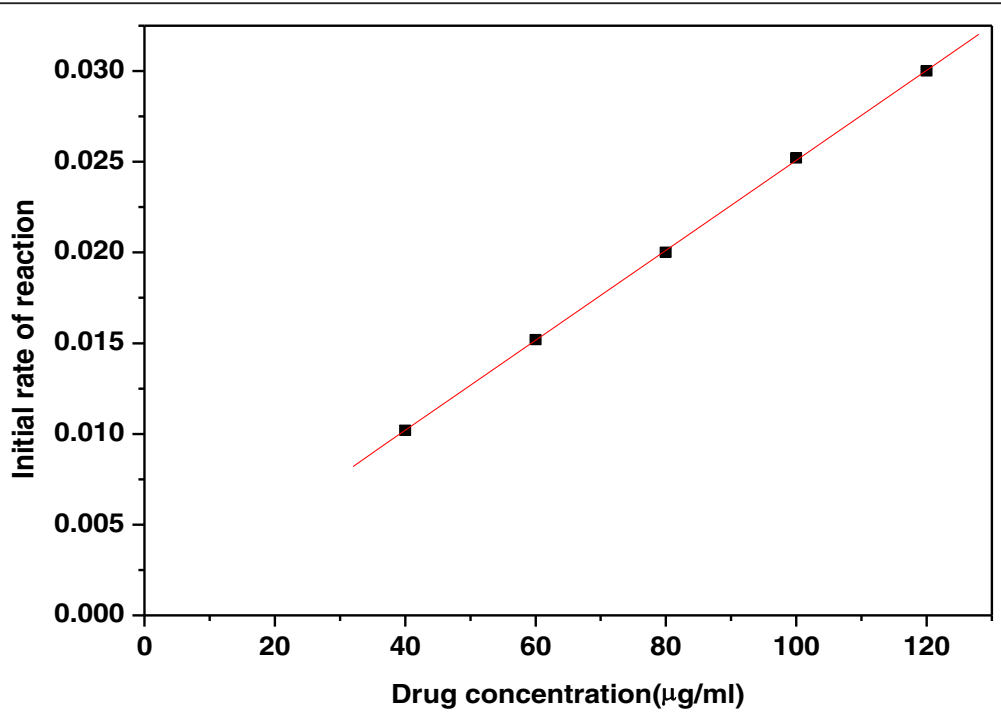

Figure 5 Calibration plot of the initial rate of reaction versus drug concentration. 


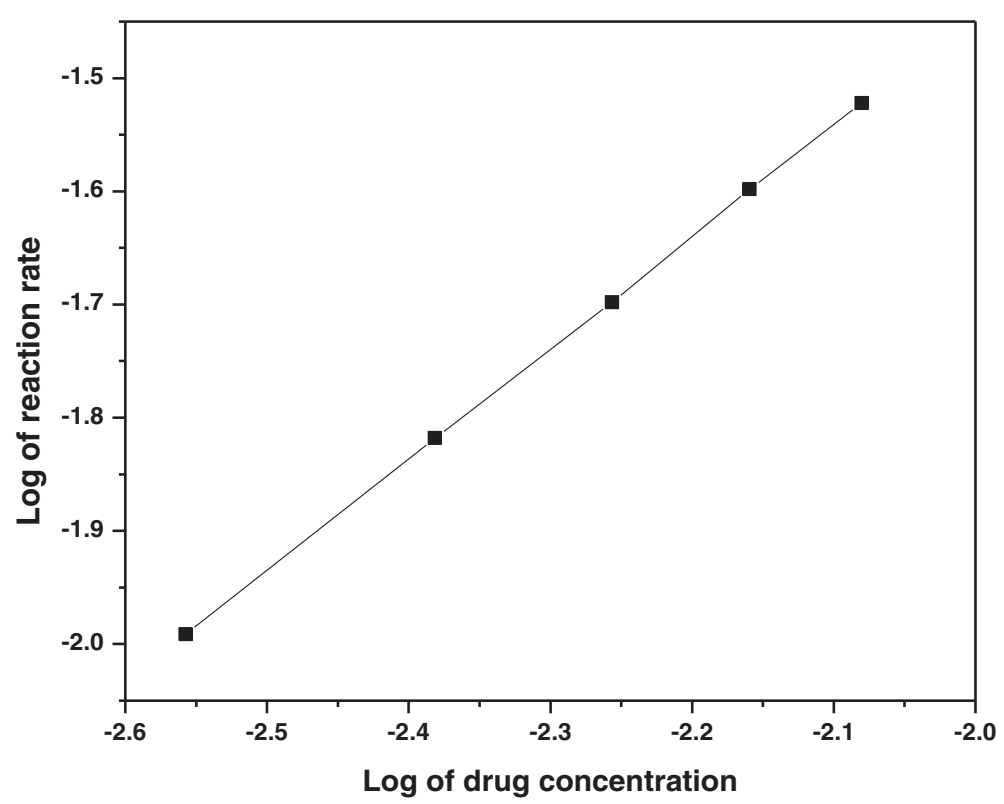

Figure 6 Plot of log of reaction rate versus log of drug concentration (mol/l).

of condensation product, giving water and $\mathrm{H}^{+}$as byproduct. The intensity of colour decreases with time (Figure 2) and provides a basis for kinetic study. The decrease in the intensity of yellow colour and hence absorbance is perhaps due to partial decomposition of the reaction product into the reagents on standing. This was confirmed by measuring the $\lambda_{\max }$ of the reaction mixture at different time intervals, viz., 5, 15, 30, $65 \mathrm{~min}$, after mixing the reagents. The $\lambda_{\max }$ has been found to remain unchanged at $420 \mathrm{~nm}$. The rate of reaction was monitored spectrophotometrically at $420 \mathrm{~nm}$ at room temperature with various concentrations of the drug, while $p \mathrm{DMAB}$ was kept in excess and constant.

\section{Optimization of reaction conditions \\ Effect of acid concentration}

The stability of the condensation product was checked with $\mathrm{HCl}, \mathrm{HNO}_{3}$, oxalic acid and $\mathrm{H}_{2} \mathrm{SO}_{4}$. The best results were obtained when $\mathrm{H}_{2} \mathrm{SO}_{4}$ was used. After selecting $\mathrm{H}_{2} \mathrm{SO}_{4}$, the stability was checked with its varying concentrations. Lower acid concentrations gave low absorbance values, while absorbance declined with increasing acid concentrations beyond $0.5 \mathrm{M} \mathrm{H}_{2} \mathrm{SO}_{4}$. The best results were obtained with $0.5 \mathrm{M} \mathrm{H}_{2} \mathrm{SO}_{4}$ (Figure 3). For the sake of ease, the experiments were carried out with $\approx 500-\mu \mathrm{g} / \mathrm{ml}$ drug concentration.

\section{Effect of $p D M A B$ concentration}

It was found that the reaction is dependent on the $p \mathrm{DMAB}$ concentration. The absorbance of the reaction solution increases as the reagent concentration increases, and the highest absorption intensity is attained at $0.3 \%(w / v)$ reagent concentration. A higher reagent concentration up to $1 \%$ has no effect on the absorption values. Further experiments were carried out using $0.3 \%(w / v)$ of the reagent. The results obtained are shown in Figure 4 . The experiments were carried out with $\approx 600-\mu \mathrm{g} / \mathrm{ml}$ drug concentration.

\section{Reaction rate method}

A plot of the initial rate of reaction versus concentration of the drug (Figure 5) gives a straight line and serves as a

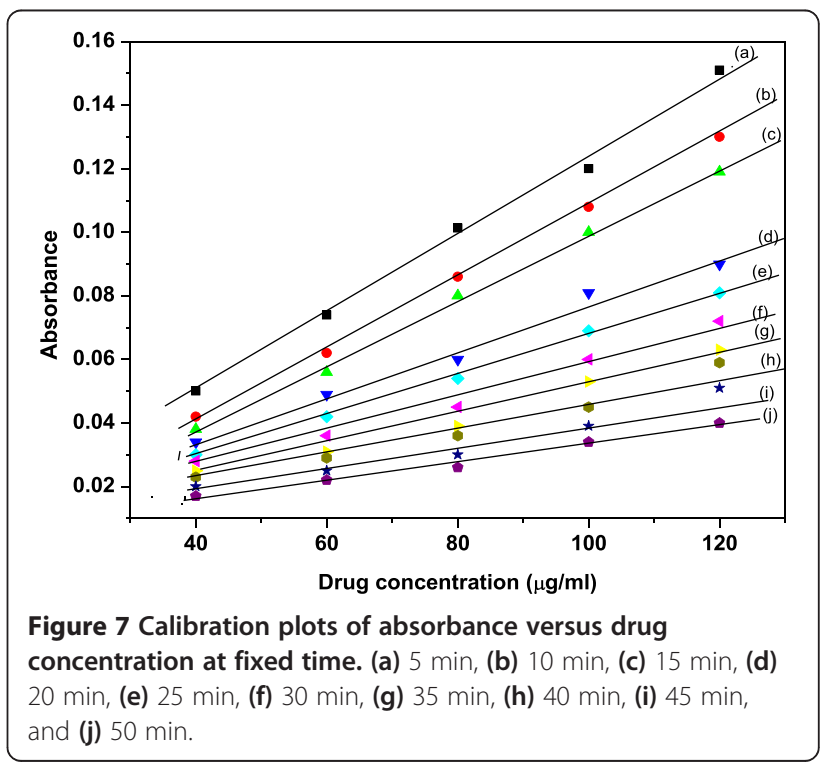


Table 1 Regression equations for the reaction rate and fixed time methods for the determination of pregabalin

\begin{tabular}{lll}
\hline Method & Regression equation & $r^{2}$ \\
\hline Reaction rate method & Rate $=2.8 \times 10^{-4}+2.48 \times 10^{-4} \times$ drug concentration & 0.999 \\
Fixed time method, time (min) & & 0.999 \\
5 & $A=0.00106+0.00123 \times$ drug concentration & 0.999 \\
10 & $A=-0.0032+0.00111 \times$ drug concentration & 0.999 \\
15 & $A=-0.0038+0.00103 \times$ drug concentration & 0.993 \\
20 & $A=0.0052+7.2 \times 10^{-4} \times$ drug concentration & 0.999 \\
25 & $A=0.0036+6.4 \times 10^{-4} \times$ drug concentration & 0.992 \\
30 & $A=0.0034+5.6 \times 10^{-4} \times$ drug concentration & 0.989 \\
35 & $A=0.003+4.9 \times 10^{-4} \times$ drug concentration & 0.984 \\
40 & $A=0.0032+4.4 \times 10^{-4} \times$ drug concentration & 0.979 \\
45 & $A=0.0026+3.8 \times 10^{-4} \times$ drug concentration & 0.993 \\
50 & $A=0.0046+2.9 \times 10^{-4} \times$ drug concentration &
\end{tabular}

A Absorbance.

The drug concentration is represented in $\mu \mathrm{g} / \mathrm{ml}$.

calibration curve. The rate of the reaction was calculated from the variable time method (Presez-Bendito and Silva 1988; Martin and Bustamante 1993) of measurement as $\Delta A / \Delta t$, where $A$ is the absorbance, and $t$ is the time in seconds. In the present study, $\Delta A / \Delta t$ was obtained by dividing the absorbance measured $300 \mathrm{~s}$ (5 minutes) after mixing the drug and the reagent solutions by $300 \mathrm{~s}$, assuming that the absorbance of the coloured product at $t=0$ is zero. The regression equation for the reaction rateversus-concentration $(\mu \mathrm{g} / \mathrm{ml})$ graph is

Table 2 Evaluation of accuracy and precision by the proposed method: determination of PGB in pharmaceutical preparations

\begin{tabular}{|c|c|c|c|c|c|}
\hline Method & Amount taken $(\mu \mathrm{g} / \mathrm{ml})$ & Amount ${ }^{a}$ found $(\mu \mathrm{g} / \mathrm{ml})$ & \%Recovery & SD & RSD (\%) \\
\hline \multirow[t]{5}{*}{ Reaction rate method } & 40 & 39.32 & 98.3 & 1.071 & 2.7 \\
\hline & 60 & 59.08 & 98.46 & 1.318 & 2.2 \\
\hline & 80 & 80.58 & 100.7 & 1.714 & 2.1 \\
\hline & 100 & 96.04 & 96.04 & 2.210 & 2.3 \\
\hline & 120 & 120.64 & 100.53 & 0.724 & 0.6 \\
\hline \multicolumn{6}{|c|}{ Fixed time method, time ( $\min$ ) } \\
\hline \multirow[t]{5}{*}{5} & 40 & 39.92 & 99.8 & 1.081 & 2.5 \\
\hline & 60 & 59.83 & 99.7 & 1.325 & 2.2 \\
\hline & 80 & 81.51 & 101.89 & 1.756 & 2.1 \\
\hline & 100 & 97.09 & 97.09 & 2.22 & 2.2 \\
\hline & 120 & 121.89 & 101.5 & 0.72 & 0.5 \\
\hline \multirow[t]{5}{*}{10} & 40 & 40.10 & 100.25 & 1.085 & 2.6 \\
\hline & 60 & 58.28 & 97.13 & 0.492 & 0.8 \\
\hline & 80 & 80.20 & 100.25 & 1.750 & 2.1 \\
\hline & 100 & 99.87 & 99.87 & 1.356 & 1.3 \\
\hline & 120 & 120.6 & 100.5 & 0.734 & 0.6 \\
\hline \multirow[t]{5}{*}{15} & 40 & 40.90 & 102.25 & 0.50 & 1.2 \\
\hline & 60 & 57.72 & 96.21 & 1.004 & 1.7 \\
\hline & 80 & 82.32 & 102.9 & 2.129 & 2.5 \\
\hline & 100 & 101.25 & 101.25 & 1.337 & 1.3 \\
\hline & 120 & 119.70 & 99.75 & 0.811 & 0.6 \\
\hline
\end{tabular}

${ }^{\mathrm{a} A n}$ average of six determinations. 


$$
\begin{aligned}
\text { Rate }= & 2.8 \times 10^{-4}+2.48 \times 10^{-4} \text { drug conc. }(\mu \mathrm{g} / \mathrm{ml}), \\
& \mathrm{r}^{2}=0.999
\end{aligned}
$$

A plot of $\log$ of reaction rate versus log of drug concentration gives a straight line (Figure 6) which shows that the reaction rate of the drug obeys the following equation:

$$
\text { Rate }=K^{\prime}[\text { drug }]^{n},
$$

where $K^{\prime}$ is the rate constant, $n$ is the order of the reaction and the drug concentration is in $\mathrm{mol} / \mathrm{L}$.

Taking logarithms of Equation (1),

$$
\begin{aligned}
& \log \text { rate }=\log K^{\prime}+n \log [\text { drug }] \\
& \log \Delta A / \Delta t=\log K^{\prime}+n \log [\text { drug }] \\
& \log \Delta A / \Delta t=-3.5664+0.98 \log [\text { drug }] \\
& \quad \mathrm{r}^{2}=0.999 .
\end{aligned}
$$

Thus, $K^{\prime}=0.00027$, and the reaction is first order $(n=0.98)$ with respect to drug concentration.

\section{Fixed time method}

Change in absorbance with time was followed for different concentrations of the drug. At a fixed time, which was accurately determined, the absorbance was measured. Calibration graphs of absorbance versus initial concentrations of the drug at fixed times of $5,10,15,20, \ldots, 50 \mathrm{~min}$ were drawn (Figure 7). The correlation coefficients of the curves were calculated. The regression equations for the calibration graphs corresponding to different fixed times are given in Table 1.

\section{Validation of the proposed methods}

Two different methods were tried to construct the calibration curves for the determination of the drug from the rate data, reaction rate method and fixed time method. The regression equations were calculated for every calibration curve. It is evident that in both methods, there is an excellent correlation between the analytical parameter and the concentration of the drug. The high correlation coefficients $\left(r^{2}\right)$ obtained for most of the calibration curves indicate high linearity in the range 40 to $120 \mu \mathrm{g} / \mathrm{ml}$, and hence, these are suitable methods for the assay of the drug. The above methods were performed in the concentration range of 40 to $120 \mu \mathrm{g} / \mathrm{ml}$. At higher concentrations, Beer's law is not obtained.

\section{Precision and accuracy}

The precision, accuracy and the applicability of the proposed methods were evaluated by measuring five independent samples of pregabalin in pharmaceutical preparations (tablet form) at 40, 60, 80, 100 and $120-\mu \mathrm{g} / \mathrm{ml}$ drug concentrations. Six replicate measurements were made for each concentration. The precision and accuracy were evaluated in terms of the standard deviation and percent recovery. The results are given in Table 2. The calculated relative standard deviations are around $2 \%$ for most of the concentrations studied (except for $40 \mu \mathrm{g} / \mathrm{ml}$ where it reaches up to $2.7 \%$ ), indicating excellent precision of the proposed methods. The percent recovery has been between $96.04 \%$ and $102.9 \%$, indicating a close agreement between the measured and true values. Hence, the proposed methods will be effective for the determination of pregabalin in pharmaceutical formulations. The condensation reaction between the drug and the reagent involves the primary aliphatic amine group. The absence of primary aliphatic amine group in the common excipients of the drug namely lactose monohydrate, talc, gelatin, maize starch and glucose eliminates any chances of interferences in the determination of the drug because of their inability to react with the reagent. The excellent RSD and \%recovery values obtained with samples of pharmaceutical formulations confirm that there is no potential interference of these excipients on the proposed methods.

\section{Conclusion}

The proposed methods are simple which preclude any use of harmful and costly solvents and reagents. \&b_k'p-Dimethylaminobenzaldehyde is a suitable reagent for the spectrophotometric determination of pregabalin. It is not only cheap and safe but also is available in any analytical laboratory with excellent shelf life. The procedure of the proposed methods is simple and time saving. No tedious procedures, extractions, heating and long standing times etc. are involved. The proposed method is sensitive, accurate and reproducible; requires simple apparatus for its performance; and consequently is suitable for routine quality control of the drug.

\section{Competing interests}

The authors declare that they have no competing interests.

\section{Authors' contributions}

All authors read and approved the final manuscript.

\section{Author details}

${ }^{1} \mathrm{PG}$ Department of Chemistry, University of Kashmir, Srinagar, Jammu and Kashmir 190006, India. ${ }^{2}$ University Science Instrumentation Centre, University of Kashmir, Srinagar, Jammu and Kashmir 190006, India.

Received: 1 May 2013 Accepted: 29 October 2013

Published: 02 Dec 2013

\section{References}

Adegoke OA, Nwoke CE (2008) Spectrophotometric determination of hydralazine using p- dimethylaminobenzaldehyde. J Iranian Chem Soc 5:316

Adegoke OA, Umoh OE (2009) A new approach to the spectrophotometric determination of metronidazole and tinidazole using p-dimethylaminobenzaldehyde. Acta Pharm 59:407-419

Bali A, Gaur P (2011) A novel method for spectrophotometric determination of pregabalin in pure form and in capsules. Chem Central J 5:59

Barona R, Brunnmüllerb U, Brasserb M, Mayc M, Bindera A (2008) Efficacy and safety of pregabalin in patients with diabetic peripheral neuropathy or postherpetic neuralgia, Open-label, non-comparative, flexible-dose studies. Eur J Pain 12:850 
Gujral RS, Manirul Haque SK, Kumar S (2009) A novel method for the determination of pregabalin in bulk pharmaceutical formulations and human urine samples. Afr J Pharm Pharmacol 3:327-334

Hamandi K, Sander JW (2006) Pregabalin: a new antiepileptic drug for refractory epilepsy. Seizure Eur J Epilep 15:73

Martin A. Bustamante P (1993) Physical Pharmacy P: Physical Chemical Principles in the Pharmaceutical Sciences, 4th edition. Lea and Febiger, Philadelphia PA, p 287

Onal A (2009) Development and Validation of Selective Spectrophotometric

methods for the determination of Pregabalin in pharmaceutical preparation. Chin J Chem 27:781-786

Onal A, Sagirli O (2009) Spectrophotometric and spectrofluorimetric methods for the determination of pregabalin in bulk and pharmaceutical preparation. Mol Bimol Spectros 72:68-71

Presez-Bendito D, Silva M (1988) Kinetic Methods in Analytical Chemistry. John Wiley and Sons, New York, pp 44-45. Ch.11

Reddy AJP (2013) New spectrophotometric determination of pregabalin bulk and Pharmaceutical dosage form. J Drug Discov and Therap 1:56-58

Sowjanya K, Thejaswini JC, Gurupadayya BM, Indu Priya M (2011) Spectrophotometric determination of Pregabalin using 1, 2-Napthaquinone4-sulfonic acid Sodium and 2, 4 dinitrophenyl hydrazine in pharmaceuticaldosage form. Der Pharmacia Lettre 3:47-56

Tassone DM, Boyce E, Guyer J, Nuzum D (2007) Pregabalin: a novel gammaaminobutyric acid analogue in the treatment of neuropathic pain, partial-onset seizures, and anxiety disorders. Clin Ther 29:26

10.1186/2093-3371-4-22

Cite this article as: Najam et al.: Kinetic spectrophotometric determination of an important pharmaceutical compound, pregabalin Journal of Analytical Science and Technology 2013, 4:22

\section{Submit your manuscript to a SpringerOpen ${ }^{\circ}$ journal and benefit from:}

- Convenient online submission

- Rigorous peer review

- Immediate publication on acceptance

- Open access: articles freely available online

- High visibility within the field

- Retaining the copyright to your article 